\title{
Complex humic product LIGNOHUMATE: application efficiency on garden crops
}

\author{
Kokhan S.K. \\ LIGNOGUMAT LLC, St-Petersburg, Russia, ksk@lignohumate.ru \\ Keywords: agriculture, apple, peach
}

doi: 10.36291/HIT.2019.kokhan.119

Humic products as an independent type of agrochemicals are increasingly expanding their presence in modern agricultural technologies, including gardening. They have long proved their effectiveness not only for territories with a favorable climate and high intensity of agriculture, but also under less favorable conditions, in particular in areas of arid steppes and semi-deserts with semi-intensive and extensive farming. And this interest is continuously growing up due to the widespread climate aridization in recent decades.

For over 25 years, our Group of Companies conducted numerous researches on the use of our product "Lignohumate" on a variety of crops in various soil and climatic conditions, including areas with insufficient moisture and high air temperatures.

Being of a practical use in agriculture for more than twenty years, "Lignohumate" has proved its effectiveness. Application in combination with plant protection products provides reliable yield increases. Although the main focus of Group of Companies' products application for decades has been and remains field crops, but recently agricultural producers show more interest in gardening as well. Therefore we initiated the test program for Lignohumate on pome and stone fruit crops, namely, apple and peach. These crops grow in certain climatic zones. For this long-term study, the Crimean Peninsula and the corresponding farms were selected.

This research is carried out under the supervision of the All-Russian National Scientific Research Institute of Viticulture and Enology "Magarach" Russian Academy of Science. The results showed, that when growing fruits, the additional yield reaches 5-6 t/ha. The effect of Lignohumate on the quality of the obtained production is even more pronounced (increase in content of sugar and vitamins on 10-15\%).

Due to the low cost per hectare, the use of Lignohumate as a component of a tank mixture is highly cost-effective in of crop protection technics. 